\title{
PLACENTAL INSUFFICIENCY
}

\author{
J. C. McClure Browne, B.Sc., M.B., B.S., F.R.C.S.Ed., F.R.C.O.G. \\ Professor of Obstetrics and Gynacology, University of London; Director, Department of Obstetrics and Gynacology, \\ Hammersmith Hospital, London, W.12
}

THE term placental insufficiency has been increasingly used in recent years in Britain to describe a condition where the fotus is particularly at risk, or dies, antepartum, intrapartum or sometimes postpartum, without trauma. Postmortem examination of the child shows that it is entirely healthy and the only changes demonstrable are those of anoxia, namely multiple petechial hæmorrhages, and the presence of meconium and liquor in the lungs. The placenta may show disturbance, for example infarction or abruptio, or it may be unduly small. On the other hand it may seem perfectly normal. Such silent intra-uterine death is common in pre-eclamptic toxæmia or in hypertension, and it is occasionally seen when the only abnormality is that the pregnancy is prolonged beyond the normal span.

\section{Placental Ischæmia}

On the basis of animal experiments Page (1939), Bastiaanse and Mastboom (1949) and Beker (1949) all suggested that placental ischæmia was the causative factor. Evidence of the occurrence of placental ischæmia in the human has however only comparatively recently been presented. Greenfield, Shephard and Whelan (I95I) calculated that to supply the oxygen requirements of a fotus weighing $3,000 \mathrm{~g}$., $350 \mathrm{ml}$. of maternal blood must flow through the placental bed each minute. Villee (1954) reached almost the same conclusion. Assali, Douglas, Baird, Nicholson and Suyemoto (1953) inserted a catheter in a uterine vein in the human and found, using nitrous oxide and the Fick principle, that at $3^{8}$ weeks the amount of maternal blood flowing through the uterus was $750 \mathrm{ml}$. per minute. Metcalfe, Romney, Ramsey and Reid (1953), by a similar method found a slightly lower figure. Our own work (Browne and Veall, 1953) showed that under normal conditions at $3^{8}$ weeks 600 $\mathrm{ml}$. of maternal blood were supplied to the placenta each minute, so that it seemed that the major portion of blood entering the uterus went to the placenta. Details of our technique have been published elsewhere, but it may be of interest to recall it in general terms.
The situation of the placenta within the uterus is first determined by outlining the area of the uterus which shows greatest radio-activity after an intravenous injection of 10 microcuries of radiosodium ${ }^{24} \mathrm{Na}$. If the placenta or part of it is found to be situated on the anterior wall of the uterus, it is then possible to investigate further. After the lapse of a few days to allow elimination of all radioactivity due to the placental localization, 5 microcuries of ${ }^{24} \mathrm{Na}$ are injected into the intervillous space, and the time taken for the injected sodium to be carried away by the circulation is recorded. In a normal healthy woman at 38 weeks half of the injected sodium is removed in about 20 seconds. If hypertension or toxæmia is present the rate of clearance is substantially reduced, so that half of the injected dose may require as much as 607 seconds for its removal. This shows very clearly? that in the presence of hypertension or of preeclamptic toxæmia there is a measurable degree of placental ischæmia. Morris, Osborn and Wright (1955), using a modification of our technique, showed that a similar reduction in blood flow occurred in the uterine muscle in toxæmia, and we ourselves showed that the same occurred in the presence of hypertension without toxæmia. Cox and Chalmers (1953) and Johnson and Clayton (1955) have also shown that in these conditions transfer of sodium across the placenta to the fœtus is considerably slowed, and Clemetson and Churchman (1954) found that the transfer of amino-acids was similarly impaired. On the other side of the placenta Walker and Turnbull (1953) showed that in these conditions the fœetus is short of oxygen. It is clear therefore that in toxæmia and hypertension there is placental impairment which may amount to insufficiency.

In our own series, although the amount of maternal blood (normally $600 \mathrm{ml}$. per minute), was reduced in cases of toxæmia or hypertension to as little as $200 \mathrm{ml}$. per minute, no babies were lost. It is apparent therefore that under normal condiconditions the placenta has a very considerable functional reserve, and moreover that the fœtus has various means of counteracting the adverse effects of placental insufficiency. ' Only when the 
placental function is very seriously impaired, and the fotus has used to the full all its powers of compensation, will fotal death occur.

\section{Diminished Placental Permeability}

Impairment of the maternal circulation to the placenta is one cause of placental insufficiency. Another cause is diminished placental permeability. Flexner, Cowie, Hellman, Wilde and Vosburgh (1948) showed that the rate of transfer of sodium from mother to fotus is impaired in late pregnancy, and the nearer to term the greater the degree of impairment. This seems to be a normal ageing process in every placenta, and is aggravated if the pregnancy goes beyond term.

\section{Liquor Volume}

Recent work by Elliott and Inman (196I) in my own Department has shown that the volume of the liquor amnii reflects the functional capacity of the placenta. Thus they found that in a healthy woman the volume of the liquor reached a peak $(\mathrm{I}, \mathrm{I} 00 \mathrm{ml}$.) at 37 weeks, diminishing steadily thereafter until at 42 weeks there was only about $300 \mathrm{ml}$. altogether. Every clinician knows from his own experience that in some cases of prolonged pregnancy when the membranes rupture there is virtually no liquor, and what little there is is thick and stained with meconium. In pre-eclamptic toxæmia and in hypertension Elliott and Inman found that the volume of liquor at 37 weeks was less than in the normal woman (approximately $800 \mathrm{ml}$.) and the reduction in volume proceeded more rapidly than normal, so that volumes of 100 to $200 \mathrm{ml}$. were found between 40 and $4 \mathrm{I}$ weeks. Elliott's findings suggest that the volume of the liquor amnii reflects accurately the functional state of the placenta, and volumes below $300 \mathrm{ml}$. suggest that the fotus is in grave danger from placental insufficiency.

\section{Twin Pregnancy}

Though I have not yet been able to prove it I strongly suspect that placental insufficiency occurs particularly in twin pregnancy, and that in this case it is of dual origin, for Morris, Osborn, Wright and Hart (1956) found that uterine blood flow was somewhat slower in twin pregnancy, and undoubtedly they combined weights of the fotuses being greater than that of a single fotus there is a greater demand for oxygen to cross the placenta. I consider therefore that in twin pregnancy the optimum duration is 38 weeks and not 40 weeks. In other words that if 'term' for a single pregnancy is 40 weeks it is 38 weeks for a twin pregnancy.

Because both hypertension and postmaturity impair the efficiency of the placenta it will be evident why these two conditions when combine carry a considerable risk for the fœetus.

\section{Other Factors}

Several other factors impair the efficiency of the placenta:

I. Age. There is good evidence that the bloof pressure rises steadily with age. Thus in a surveye of the blood pressure of 7,000 primigravidx (Browne 1961) the mean blood pressure at the age of 20 was $124 / 73$, rising steadily to $130 / 76$ at the age of 40 . It is also well known clinically that the older woman runs a greater risk of losing her babÿ from no obvious cause. It seems reasonablew when we remember the effect of hypertension of the maternal placental circulation, to suppose that the less resilient circulation of the older woman. should give rise to placental insufficiency.

2. Gravidity. There seems to be no doubt that the primigravida and grand multipara are more likely to have a silent intrauterine fotal death than women having their second or third children. It may be that in the primigravida the circulatory responses to the demands of pregnancy are not fully met as pregnancy is a new experience for her은 The grand multipara on the other hand, though knowing what is demanded of her, is unable cause of a degenerating vascular system to respond fully to these demands.

3. Exercise. The beneficial effects of rest in thes management of toxæmia and of hypertension in pregnancy have been known for generations. Morriso and others (1956) showed that exercise resulted in尺 considerable slowing of the uterine circulation. $\mathrm{He}_{\vec{S}}^{\vec{B}}$ first determined the rate of clearance of ${ }^{24} \mathrm{Na}$ from the uterine muscle of women at rest, then during? exercise, and finally at rest again. In every case the slowing of uterine circulation produced byo exercise was very marked, and moreover the return. to normal on cessation of exercise was slow. Ito will readily be seen that the effect of physical activity on a uterine and placental circulation? already impaired by hypertension or prolonged pregnancy may be lethal for the fotus.

4. Labour. Wright, Morris, Osborn and Hart (1958) also showed very clearly that during labour the uterine circulation was impaired and that the degree of impairment increased the longer the labour went on. Caldeyro Barcia (1959), using our own method, showed that during a uterinew contraction the maternal placental blood flow was? diminished. This may well account for many ofo the cases of fœtal distress and even fœtal death during labour in women suffering from preeclampsia and hypertension.

Thus we can say that placental insufficiency may. occur in the following conditions: age over $30, \frac{?}{\circ}$ primigravida, toxæmia, hypertension, chronic 
nephritis, diabetes, prolonged pregnancy, physical exercise, labour, and in twin pregnancy after $3^{\text {b }}$ weeks.

\section{Diagnosis}

How can placental insufficiency be detected ? Scott Russell, Payne and Coyle (1957) have shown that when serial determinations of pregnanediol excretion are made during pregnancy there is a steady rise as the months go by until the last two weeks or so before delivery, when it falls. In cases of placental insufficiency, however, pregnanediol excretion, which may initially rise quite normally, never reaches the normal peak, and some two weeks or so before the child dies in utero pregnanediol excretion falls. Zondek and Goldberg (1957) have shown that urinary œstriol elimination can be used in late pregnancy as a qualitative test of placental function. Elliott and Inman (I96I) as mentioned above have shown that the volume of the liquor amnii reflects the functional efficiency of the placenta. Dawkins, MacGregor and McLean (1959) suggested that the placental enzyme iso-citric dehydrogenase could be used as an index of placental function. This work, however, has not yet been confirmed, and there is great need for a satisfactory laboratory test to determine placental function.

From the clinical point of view the presence of any one of the conditions listed above should make the obstetrician aware of the possibility of fœtal death occurring. Certain clinical observations give an indication of impending fœtal death.

I. Weight loss. The average weight gain throughout pregnancy is of the order of 24 pounds, and in the last four weeks of pregnancy weight is gained at the rate of about I pound per week. For a long time we have been aware of the significance of a sudden excessive weight gain as an indication of fluid retention and impending toxæmia. In placental insufficiency it may be noted that weight gain is not maintained, and indeed the overall gain of weight in pregnancy may be much less than normal. In placental insufficiency it may be noted that weight gain ceases and there may even be an actual loss of weight of I or 2 pounds. When this occurs and there is no other explanation for it such as vomiting, fœtal death is likely to occur within the next ten days or so. In cases where placental insufficiency seems likely it is desirable therefore to weigh the woman daily, so that on any one day her weight may be compared with that of the week before. A cessation of weight gain or a sustained weight loss may indicate the necessity for early delivery of the child by whatever means is appropriate.

2. Abdominal girth. The girth of the abdomen at term is on the average 40 in., and at 36 weeks
36 in., though due allowance must be made of course for any obesity. If the abdominal girth, which has been increasing steadily, begins to diminish, this again is an indication that the child should be delivered within a week or so.

3. Diminution in the amount of liquor. Wrigley (1939) in discussing postmaturity pointed out that the same observer palpating the uterus daily may detect a diminution in the amount of liquor. This may indicate the necessity for delivery. Elliott's method of determination of the liquor volume is not at present universally applicable.

\section{Management}

When placental insufficiency is suspected and the fotus is still premature, it is advisable to keep the woman at rest in bed, so as to favour the placental circulation. On the whole diuretics are best avoided as their use may mimic weight changes due to placental deterioration and so lead the obstetrician to effect delivery before it is necessary. The chances of survival of an infant born prematurely depend on the stage of gestation rather than on its birth weight, which in any case will not increase if the placenta cannot keep pace with fotal demands. Decision as to the best time to effect delivery demands a nice obstetric judgement, weighing on the one hand the risks of prematurity against those of placental insufficiency on the other. Taking these all into account, the time comes when delivery seems imperative if a live child is to be secured.

In many cases surgical induction of labour is the method of choice. When this is performed by artificial rupture of the membranes, careful note should be taken of the volume, consistency and appearance of the liquor so obtained. If the liquor escapes freely and is colourless, and there is plenty of it, placental insufficiency is not likely and delivery can be awaited calmly. On the other hand when the liquor is scanty, thick and stained with meconium the fotus is already at risk because of placental insufficiency, and a special watch should be maintained on the fœtal heart until the child is safely delivered. It should be remembered that the contractions of labour themselves impair placental function, and may be the last straw for a fotus already embarrassed by placental insufficiency from some other cause such as toxæmia or prolonged pregnancy. For the same reason a 'pitocin drip' should be avoided. When the infant is an especially precious one, e.g. in the elderly primigravida, it may be deemed desirable to proceed straight away to Cæsarean section in the interests of the child.

Finally, let me emphasize that the combination of two or more of the conditions which produce placental insufficiency is particularly hazardous 
for the fotus, and the obstetrician should be ready to intervene by whatever means are appropriate in order to secure a living child.

\section{Summary}

I. There is a considerable amount of clinical and experimental evidence to suggest that placental insufficiency is a common cause of intra-uterine fœtal death.

2. Placental insufficiency may occur in a variety of clinical conditions, of which toxæmia and prolonged pregnancy are the commonest.

3. Age, parity, physical exercise, and labour also affect placental function.

4. Diagnosis is mainly based on clinical observa- tion. There may be failure of the woman to gaire weight (or loss of weight), or failure of increase of abdominal girth (or decrease), or diminution in the्ष amount of liquor amnii. All three often are detected together. Laboratory determination of: the rate of pregnanediol excretion or cestrio $\overrightarrow{5}$ excretion may help, as may the calculation of the volume of liquor amnii.

5. Induction of labour, or in some cases Cæsarean section, is indicated, taking into accoun the risks of prematurity.

6. The combination of two or more conditions? each of which in itself conduces to placental in sufficiency, may be lethal for the fœtus unless $\vec{\omega}$ delivered without delay.

\section{REFERENCES}

Assali, N. S., Douglass, R. A., Baird, W. W., Nicholson, D. B., and SuYemoto, R. (r 953): Measurement of Uterin $\dot{\delta}_{0}$ Blood Flow and Uterine Metabolism, Amer. $\mathcal{~ . ~ O b s t e t . ~ G y n e c . , ~ 6 6 , ~} 248$.

Bastianine, M. A. van Bouwdijk, and Mastboom, J. L. (1949): Ned. Geneesk., 93, 2609.

BEKER, J. C. (1948): Etiology of Eclampsia, F. Obstet. Gynac. Brit. Emp., 55, 756.

Browne, J. C. McClure, and Veall, N. (1953): Maternal Placental Blood Flow in Normotensive and Hypertensive Women, Ibid., 60, r4I.

- (1961): Survey of Eclampsia-Clinical Aspects, Path. Microbiol., 24, 542.

Caldeyro-Barcia, R. (r957): In 'Physiology of Prematurity'. Transactions of ist Conference, p. 2 i 9. New York:Josiah Macy Foundation.

Clemetson, C. A. B., and Churchman, J. (1953): Oxygen and Carbon Dioxide Content of Umbilical Artery and Veing Blood in Toxæmic and Normal Pregnancy, $\mathcal{F}$. Obstet. Gynac. Brit. Emp., 60, 335.

Cox, L. W., and Chalmers, T. A. (1953): The Effect of Pre-eclamptic Toxæmia on the Exchange of Sodium in the body and the Transfer of Sodium Across the Placenta, Measured by $\mathrm{Na}^{24}$ Tracer Methods, $\mathcal{F}$. Obstet. Gyn@i Brit. Emp., 60, 214.

Dawkins, M. J. R., MacGregor, W. G., and McLean, A. E. M. (1959): The Detection of Placental Degeneratirn During Pregnancy, Lancet, ii, 827.

Elliot, P., and INMAN, W. H. W. (1961): Volume of Liquor Amnii in Normal and Abnormal Pregnancy, Ibid., ii, 835

Flexner, L. B., Cowie, D. B., Hellman, L. M., Wilde, W. S., and Vosburgh, G. J. (1 948): The Permeability of the्, Human Placenta to Sodium in Normal and Abnormal Pregnancies and the Supply of Sodium to the Humañ Fetus as Determined with Radioactive Sodium, Amer. F. Obstet. Gynec., 55, 469.

Greenfield, A. D. M., Shepherd, J. T., and Whelan, R. F. (r95I): The Relationship Between the Blood Flow in the Umbilical Cord and the Rate of Fœtal Growth in the Sheep and Guinea-pig, $\mathscr{F}$. Physiol. (Lond.), Ir5, 158.

Johnson, T., and Clayton, C. G. (1955): Studies in Placental Action During Prolonged and Dysfunctional Labours Using Radioactive Sodium, F. Obstet. Gynac. Brit. Emp., 62, 5 I 3.

Metcalfe, J., Romney, S. L., RamSEy, L. H., and Reid, D. E. (1953): An Approach to the Measurement of Uterine Blood Flow in Pregnancy, $\mathcal{F}$. clin. Invest., 32, 589.

Morris, N., Osborn, S. B., and Payling Wright, H. (1955): Effective Circulation of the Uterine Wall in Late Pregnancys Measured with ${ }^{24} \mathrm{NaCl}$, Lancet, $\mathrm{i}, 323$.

,,,--- and HART, A. (1956): Effective Uterine Blood-flow During Exercise in Normal and Pre-eclamptici Pregnancies, Ibid., ii, 481 .

Page, E. (1939): The Relation Between Hydatid Moles, Relative Ischemia of the Gravid Uterus, and the Placentaig Origin of Eclampsia, Amer. . Obstet. Gynec., 37, 29.

Russell, C. S., Paine, G. F., and Coyle, Mary G. (1957): Pregnanediol Excretion in Normal and Abnormal Pregnancy, F. Obstet. Gynac. Brit. Emp., 64, 649.

VILleE, C. A. (I954): Symposia on Quantitative Biology, XIV, p. I 50, Biol. Laboratory, Cold Spring Harbor, L.I., New York.

Walker, J., and Turnbull, E. P. N. (1953): Hæmoglobin and Red Cells in the Human Fotus and their Relation to the Oxygen Content of the Blood in the Vessels of the Umbilical Cord, Lancet, ii, 312.

Wright, H. Payling, Morris, N., OsBorn, S. B., and HART, A. (I958): Effective Uterine Blood Flow During Labor, Amer. F. Obstet. Gynec., 75, 3 .

Wrigley, A. J. (1946): The Problem of 'Post-maturity', Proc. roy. Soc. Med., 39, 569.

ZoNDEK, B., and Goldberg, SARA (1957): Placental Function and Fœtal Death, $\mathscr{F}$. Obstet. Gynac. Brit. Emp., 64, I. 